\title{
Microhardness of starch based biomaterials in simulated physiological conditions
}

\author{
N.M. Alves ${ }^{\text {a,b }}$, C. Saiz-Arroyo ${ }^{\mathrm{a}, \mathrm{b}}$, M.A. Rodriguez-Perez ${ }^{\mathrm{c}}$, R.L. Reis ${ }^{\mathrm{a}, \mathrm{b}}$, J.F. Mano ${ }^{\mathrm{a}, \mathrm{b}, *}$ \\ a 3 B's Research Group - Biomaterials, Biodegradables and Biomimetics, University of Minho, Campus de Gualtar, 4710-057 Braga, Portugal \\ ${ }^{\mathrm{b}}$ Department of Polymer Engineering, University of Minho, Campus de Azurém, 4800-058 Guimarães, Portugal \\ ${ }^{\mathrm{c}}$ Department of Condensed Matter Physics, University of Valladolid, E-47011 Valladolid, Spain
}

Received 10 April 2006; received in revised form 28 June 2006; accepted 6 July 2006

\begin{abstract}
In this work the variation of the surface mechanical properties of starch-based biomaterials with immersion time was followed using microhardness measurements. Two blends with very distinct water uptake capabilities, starch/cellulose acetate (SCA) and starch/poly( $\varepsilon$-caprolactone) (SPCL), were immersed in a phosphate buffer solution (PBS) at $37.5^{\circ} \mathrm{C}$ for various times. The microhardness of the blends decreased significantly ( $\sim 50 \%$ for SPCL and $\sim 94 \%$ for SCA), within a time period of 30 days of immersion, reflecting the different hydrophilic character of the synthetic components of the blends. The dependence of microhardness on the applied loading time and load was also analysed and showed a power law dependency for SCA. Water uptake and weight loss measurements were performed for the same immersion times used in the microhardness experiments. The different swelling/degradation behaviour presented by the blends was related to the respective variation in microhardness. Moreover, complementary characterization of the mechanical properties of SCA and SPCL was accomplished by dynamic mechanical analysis (DMA) and creep measurements. Microhardness measurements proved to be a useful technique for characterizing the mechanical behaviour near the surface of polymeric biomaterials, including in simulated physiological conditions.
\end{abstract}

(C) 2006 Acta Materialia Inc. Published by Elsevier Ltd. All rights reserved.

Keywords: Microhardness; Starch blends; Swelling; in vitro degradation; Mechanical properties

\section{Introduction}

The idea of substituting synthetic polymers with natural polymers in any application and, in this way, using a renewable source, is extremely appealing. Starch is the major polysaccharide constituent of photosynthetic tissues and of many storage organs in plants [1]. Starch-based biomaterials are totally biodegradable, with an associated low cost when compared with other biodegradable polymers, are available in large quantities and, therefore have an enormous potential for environmental and clinical applica-

\footnotetext{
* Corresponding author. Address: 3B's Research Group - Biomaterials, Biodegradables and Biomimetics, University of Minho, Campus de Gualtar, 4710-057 Braga, Portugal. Tel.: +351 253604497.

E-mail address: jmano@dep.uminho.pt (J.F. Mano).
}

tions. In the last few years these kinds of systems have been proposed in our research group for different biomedical applications [2-8] including for replacement materials, controlled delivery systems, hydrophilic cements and, more recently, for scaffolds in tissue engineering applications. The proposed systems are blends of starch with ethylenevinyl alcohol copolymer (SEVA-C), cellulose acetate (SCA), poly(e-caprolactone) (SPCL) and poly(lactic acid) (SPLA) [2-8]. The combination of biocompatibility, suitable mechanical and degradation properties constitutes one of the main advantages of the starch-based blends that have been developed, showing that they have potential to be used as scaffolds in tissue engineering $[9,10]$.

Moreover, biomaterials interact with their environment at the cellular level and it is the surface of the material that directly interacts with proteins and cells [11-13]. 
Consequently, the surface mechanical properties of an implant are very important in determining cell responses $[11,12]$ and the implant behaviour will strongly depend on these properties [13]. For instance, the surface topography and surface mechanical strength of an implant can be critical to its success, because it has been shown that cell adhesion and spreading depend on these factors [12]. Being a hydrophilic polysaccharide, starch and its blends may present considerable water uptake and it is expected that the mechanical features will be different in the dry state when compared with the hydrated state, the latter being obviously more relevant in clinical applications. Some works have reported the influence of water on the mechanical properties of biomaterials (see e.g. Refs. [14,15]). However, in this case the mechanical behaviour of the surface of the material with which the cells and tissues will interact may be different from the bulk properties, especially when the hydration equilibrium is not achieved. A simple technique such as microhardness can provide a possible way to measure the actual hardness of the surface layer, which is difficult to measure by traditional techniques, such as tensile or flexural tests.

So, the aim of the present work was to use microhardness to evaluate the changes in the surface mechanical properties of starch-based blends with different swelling capabilities (SCA and SPCL), when they are immersed in a solution for different periods of time. Although some microhardness studies of starch can be found in the literature [16-18], as far as we know, this is the first time that this technique is used to characterise starch-based biomaterials after being immersed in simulated physiological fluids at body temperature.

In order to complement the characterization of the mechanical properties of the starch-based blends, their creep and dynamic mechanical properties were also investigated. Such kinds of tests allow the intrinsic viscoelastic behaviour of these polymeric systems to be analysed and could also provide information on whether any correlation exists between the bulk viscoelastic properties of the materials and their microhardness.

Parallel swelling and weight loss measurements were performed in order to study how the degradation of these starch-based biomaterials is affected by the hydrophobic or hydrophilic character of the other component and how this influences the respective mechanical properties. As reported in the literature $[19,20]$, hydrophilicity is a determining parameter in the degradation behaviour of starchbased materials.

\section{Experimental section}

Two different starch-based biomaterials were studied: a $50 / 50 \mathrm{wt} . \%$ corn starch/cellulose acetate blend (SCA) and a 30/70 wt.\% corn starch/poly(E-caprolactone) blend (SPCL). All the materials were processed into disk samples $(\phi=1 \mathrm{~cm}$, thickness $=2 \mathrm{~mm})$, by injection moulding. Samples of both materials were immersed in a phosphate buffer solution (PBS) and kept at $37.5^{\circ} \mathrm{C}(\mathrm{pH}=7.4)$, for different times (from 1 min to 30 days) in order to roughly simulate the hydration conditions in the human body, when the materials are implanted.

A Leica VMHT30 equipment was used to measure the microhardness of the samples at $\sim 20^{\circ} \mathrm{C}$ after being immersed for different times, using a Vickers diamond pyramid indenter (included angle $\alpha=136{ }^{\circ} \mathrm{C}$ ). The microhardness, $H$, was calculated from the residual projected diagonal impression by applying $H=1.854 F / d^{2}$ [21], where $d$ is the mean diagonal length of the indentation in $\mathrm{mm}$ and $F$ is the applied force in N.

For the immersed samples a loading time of $5 \mathrm{~s}$ and an indentation load of $49.03 \mathrm{mN}$ were used. For the nonimmersed samples and in order to evaluate the dependence of $H$ on time and load, measurements were made at two different indentation loads ( 9.807 and $49.03 \mathrm{mN}$ ) and for each load several loading times (from 5 to $60 \mathrm{~s}$ ) were used. The length of the resulting indentation was measured immediately after load release in order to avoid complications associated with viscoelastic recovery. At least five imprints were made in each test at randomly chosen places of the samples.

At the end of each degradation time, the samples were removed from solution, rinsed with distilled water and weighed, to determine the water uptake. The water uptake of the samples after being immersed for different times was evaluated as $\left[\left(M_{f}-M_{i}\right) / M_{i}\right] \times 100$, where $M_{i}$ is the weight of the dry sample at time $t=0 \mathrm{~s}$ and $M_{f}$ is the weight of the wet sample at immersion time $t$.

For every degradation time, the samples were dried until the weight remained constant in order to determine the weight loss. The weight loss corresponding to distinct immersion times was calculated as $\left[\left(M_{i}-M_{d}\right) / M_{i}\right] \times 100$, where $M_{i}$ is the initial weight of the sample and $M_{f}$ is the weight of the degraded (and dry) sample at time $t$.

Complementary characterization of the solid-state rheological properties of the starch blends was accomplished by creep and dynamic mechanical analysis (DMA). Nondegraded samples were analysed in the dry state. These experiments were performed using a Perkin Elmer DMA7 analyser with a controlling cooling accessory and using helium as a purge gas. The three-point bending mode was chosen: the samples, with rectangular geometry and dimensions $15 \times 4.3 \times 2 \mathrm{~mm}$, were placed in a $15 \mathrm{~mm}$ platform and a $5-\mathrm{mm}$ knife-edge probe tip provided the mechanical excitation. Sufficiently low force values were applied in all the experiments to ensure that the resultant strain was within the linear viscoelastic regime. Creep measurements were performed at $20^{\circ} \mathrm{C}$ for $48 \mathrm{~h}$. The creep stress was $3.33 \mathrm{MPa}$ for SCA and $1.21 \mathrm{MPa}$ for SPCL. After this time period the stress was removed and the samples were allowed to recover for $24 \mathrm{~h}$. Dynamic mechanical measurements were conducted between -70 and $60{ }^{\circ} \mathrm{C}$ at $2{ }^{\circ} \mathrm{C} / \mathrm{min}$ and $1 \mathrm{~Hz}$. Prior to the experiments all the necessary thermal and mechanical calibrations were performed. 


\section{Results and discussion}

\subsection{Microhardness results}

In this study microhardness tests were performed with SCA and SPCL in order to evaluate the changes occurring when these polymers are immersed in an aqueous medium for distinct periods of time; see Figs. 1 and 2. For SPCL it was found that microhardness decreased from $\sim 29.8 \mathrm{MPa}$ for a non-immersed sample to approximately $15.1 \mathrm{MPa}$ after 30 days of immersion (see Fig. 1). Fig. 2 expands the data for the first $100 \mathrm{~min}$, where it can be noted that the main decrease of the microhardness value happens in this short period of time. For SCA the microhardness decreased even more than for SPCL for the same immersion periods (Fig. 1): it decreased from $\sim 33.3 \mathrm{MPa}$ for a non-immersed sample to $1.9 \mathrm{MPa}$ after 30 days of immersion. As for SPCL, the main decrease occurred after a very short immersion time, less than 100 min (see Fig. 2).

It is known that the mechanical properties change with time due to different factors, such as swelling or degradation. In the case of SCA the variation is more dramatic essentially because the ability for water uptake of

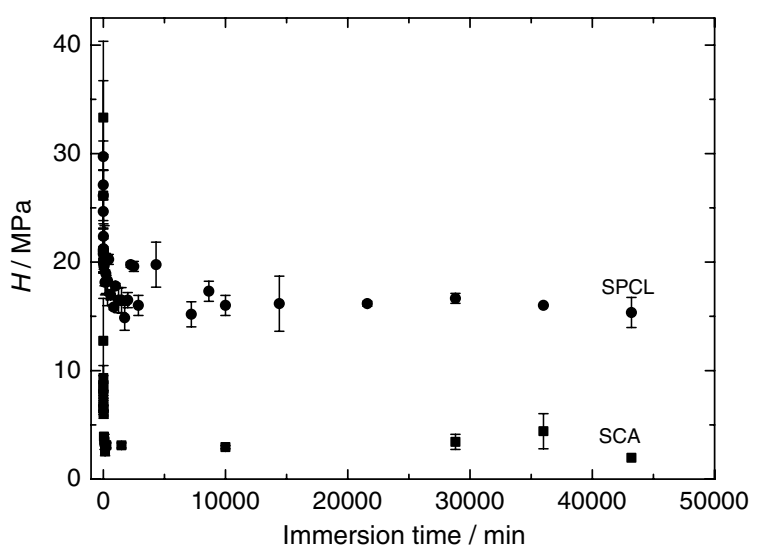

Fig. 1. Microhardness against immersion time for SPCL and SCA between 0 and 30 days. Loading time $=5 \mathrm{~s}$ and applied force $=49.03 \mathrm{mN}$.

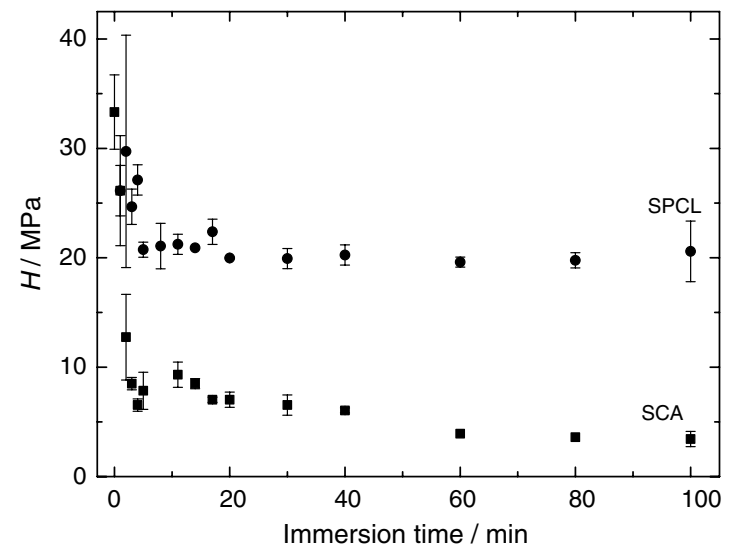

Fig. 2. Microhardness against immersion time for SPCL and SCA between 0 and $100 \mathrm{~min}$. Loading time $=5 \mathrm{~s}$ and applied force $=49.03 \mathrm{mN}$.
SCA is much higher than for SPCL, as shown in the next section.

Previous microhardness studies on non-dried starch reported that for this material the hardness is greatly influenced by the amount of water present in the sample, with the hardness values increasing with decreasing water content $[16,17]$. Water reduces the hydrogen bonding between molecules, decreasing the intermolecular forces, and hence reducing the resistance to plastic deformation [17]. The blending of starch with less hydrophilic polymers may be a way to reduce this effect, providing more mechanical integrity of the material in hydrated environments. This is the case for SPCL, where PCL has a low water uptake ability, as can be seen in the next section. For example, regarding the surface mechanical properties of PCL, it was shown that for pure microporous PCL samples the indentation resistance was virtually unchanged after 45 months of immersion in PBS [22]. This behaviour was attributed to the hydrolytic stability of PCL [22].

As pointed out in the introduction, the mechanical properties of biomaterials may change significantly when they are investigated under a simulated physiological environment [14]. The microhardness technique used in our work allows the variations in the surface mechanical properties of the analysed starch blends to be measured after being immersed and therefore these changes can be detected after a period shorter than the time needed to detect variations in the bulk properties in the dry state: in this case after only 30 days of immersion. This happens because the water uptake process, due to the absorption gradient, starts at the surface of the sample.

It should be noted that the surface for the microindentation tests was not modified because we wanted to study a surface similar to the surface of these biomaterials when implanted. However, from the SEM images of these samples (not shown), it was confirmed that the surface morphology, namely the roughness before and after immersion in PBS, did not change significantly for both materials. So the decrease in microhardness measured for the immersed samples could not be just an effect of different surface topographies.

The microhardness of SCA and SPCL dry samples was also measured in order to analyse its dependence on load and loading time; see Fig. 3. When the loading time is fixed, it can be seen that the measured hardness is load dependent for the two materials and for all the loading times. Usually for brittle materials, such as silica glass and alumina, the hardness is virtually independent of load [23]. For metals the measured hardness typically decreases with increasing load due to the indentation size effect, which has been extensively discussed in the literature [24]. However, a tendency opposite to the one previously referred to for metals is observed in Fig. 3. We believe that this behaviour could be related to the skin-core morphology developed during the injection moulding process of the samples. As the cooling rate of the skin layer is higher than the one corresponding to the core region, its degree of crystallinity and, 

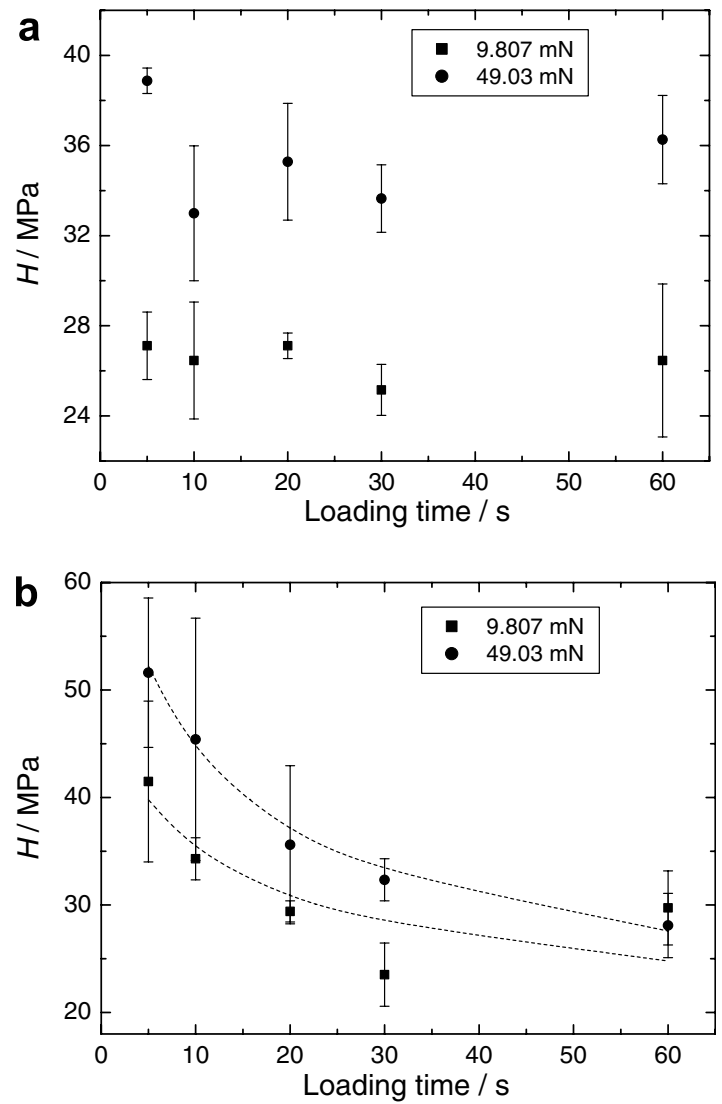

Fig. 3. Microhardness against loading time, for two different applied forces (indicated in the graphics) measured for dry (a) SPCL and (b) SCA.

consequently, its microhardness, should be lower. In fact, this behaviour was already reported [25]. When the load is higher we are increasing the penetration depth of the experiment and, due to the skin-core morphology, the microhardness should increase as seen in Fig. 3.

An important aspect concerning the surface indentation mechanism is the creep effect shown by polymeric materials [21]. The so-called creep curves, i.e. the microhardness vs. loading time plots (Fig. 3), are typically characterized by a decreasing strain rate. For many polymers this behaviour is successfully described by a power law, $H=H_{0} t^{-k}$, where $H_{0}$ is a coefficient that, for a given morphology, depends on temperature and loading stress, $k$ gives a measure of the creep rate of the material and $t$ is the loading time.

For SPCL it was not possible to fit the experimental data (Fig. 3a) to the previous equation. In fact it can be seen that, in the range of loading times used, the variation of microhardness with loading time is almost negligible, an opposite behaviour to the one commonly observed for several polymers [21]. On the contrary, for SCA the experimental data shown in Fig. $3 b$ were successfully fitted to a power law. The creep constant $k$ was calculated from the previous data, by using a conventional non-linear least squares curve fitting algorithm. A value of $k=0.2$ was obtained, independent of the applied load. For pure starch, the hardness was also shown to decrease with loading time, following a power law function [18]. A creep constant $k=6.7 \times 10^{-2}$ was obtained in this case [18]. This value is comparable, for instance, to the ones reported for PET ( $k$ between $5 \times 10^{-2}$ and $6 \times 10^{-3}$ were obtained in the work of Baltá Calleja et al. [26]). By comparing the $k$ values of SCA and pure starch it can be seen that the creep rate of SCA is much higher than that of pure starch.

\subsection{Swelling and degradation results}

The water uptake and the weight loss of both starch blends were measured for distinct immersion times; see Figs. 4 and 5. The period of time between 1 and 100 min was investigated in detail because, as shown in Section 3.1, the change in microhardness for both materials occurs especially in this short period of time. The water uptake was $\sim 9 \%$ for SPCL and $\sim 45 \%$ for SCA, after 30 days of immersion (Fig. 4a). For SCA a water uptake of $\sim 14 \%$ was measured after only $100 \mathrm{~min}$, whereas for SPCL the water uptake was just $\sim 4 \%$ for the same time period (Fig. $4 b$ ). The observed differences in the water uptake ability of the materials are mainly due to the synthetic component present in the blends. Cellulose acetate has a much higher hydrophilic character and can take up much more water than PCL. It must be pointed out that the water uptake measured in this work for both samples should be considerably higher than
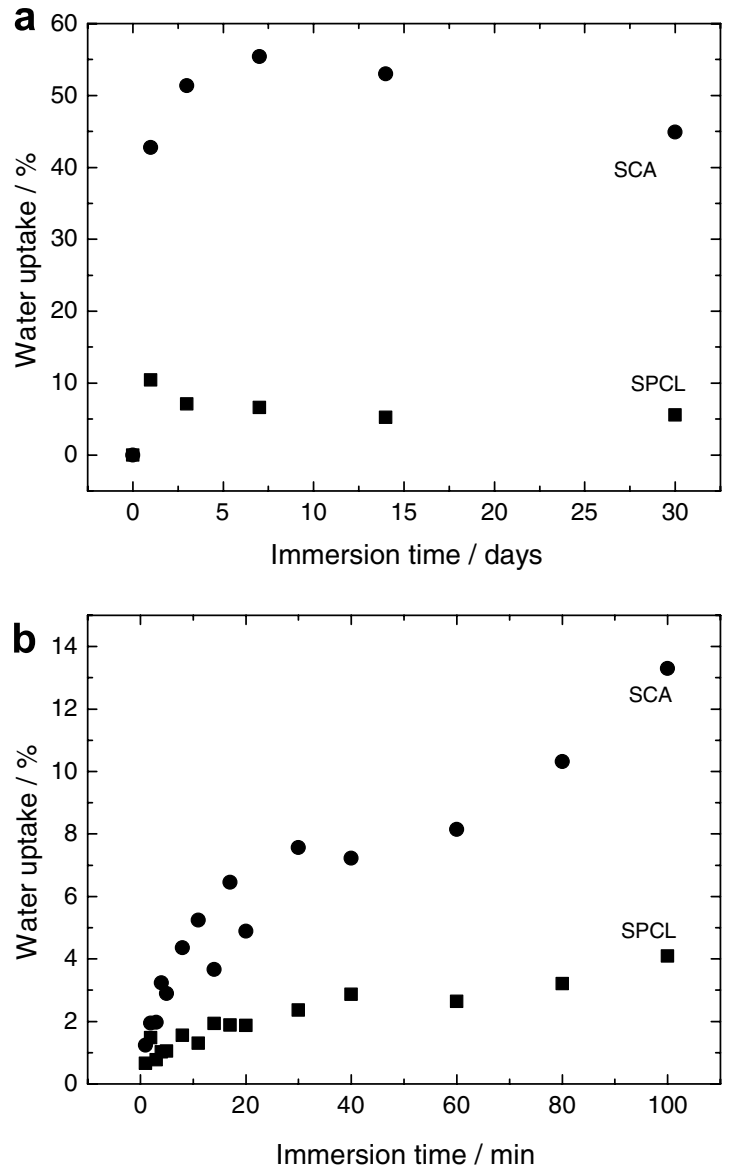

Fig. 4. Water uptake ability of SPCL and SCA for immersion times between (a) 0 and 30 days and (b) 0 and $100 \mathrm{~min}$. 

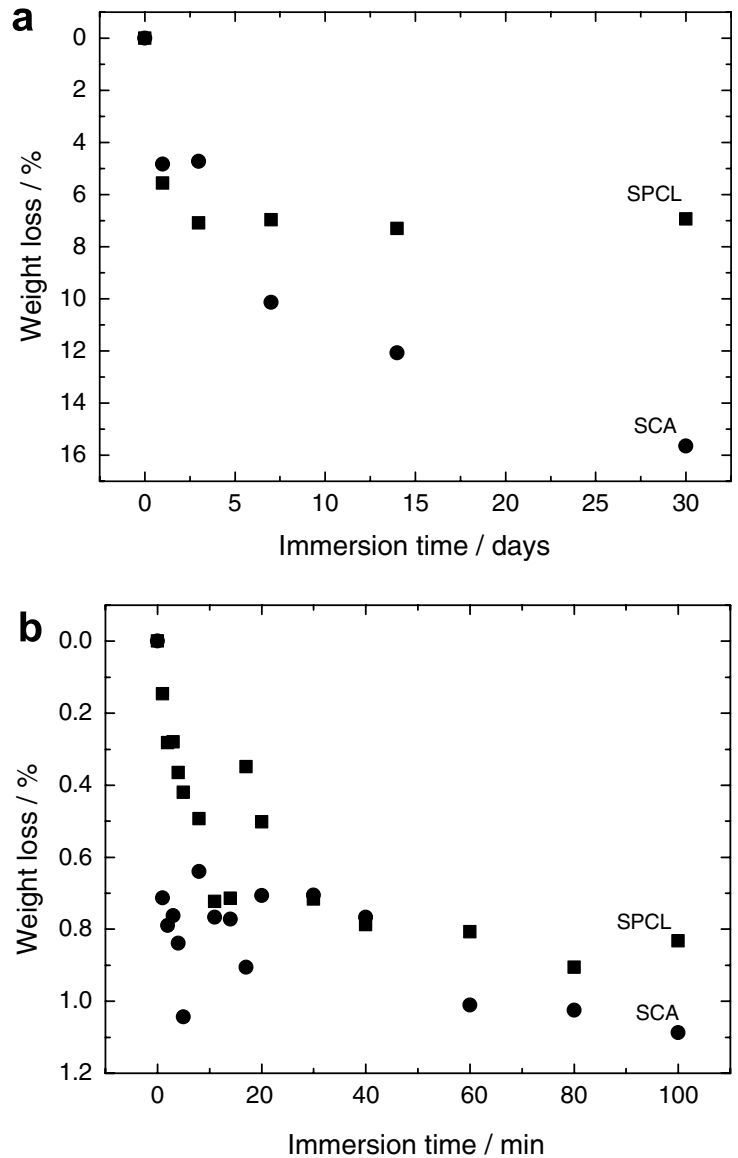

Fig. 5. Weight loss of SPCL and SCA for immersion times between (a) 0 and 30 days and (b) 0 and $100 \mathrm{~min}$.

the values that would be obtained if the same measurements were conducted in a confined environment. In fact, a biomaterial when implanted is confined by the surrounding tissue and the water uptake and swelling of the implant would be limited by this factor. This effect was already investigated in vitro for starch-based materials [27].

The weight loss was $\sim 7 \%$ for SPCL and $\sim 16 \%$ for SCA, after 30 days of immersion (Fig. 5a). The lower weight loss associated with SPCL is also related to the previously mentioned properties of this material. In fact, it has been shown that pure PCL is stable when immersed in PBS at $\mathrm{pH} 7.2$ for $\sim 1$ year [28]. The major weight loss occurs in the first week for both materials and after 7 days the weight loss of SCA is higher than for SPCL. The weight of SPCL remained approximately constant after that time period. The weight loss for short times is almost negligible (Fig. 5b). After 100 min the measured weight loss values were $\sim 1.1 \%$ for SCA and $\sim 0.8 \%$ for SPCL. Similar weight loss values and degradation rates have been found for SPCL and SCA elsewhere [29-31].

The hydrolytic degradation behaviour of starch based blends has been analysed in several works $[3,29,30,32,33]$. It was reported that in the first stage of degradation of the starch-based blends a loss of plasticizers occurs, mostly glycerol, which are used in the blends to enable the materials processing. Then the elimination of low molecular weight chains is observed resulting from the thermo-oxidative degradation that occurred during the processing stages. For longer times, i.e. substantially longer than 30 days $[3,29,30,32,33]$, the chemical degradation of the starch and synthetic phases occurs with backbone scission and leaching of low molecular weight chains to the solution. So, the weight loss measured for both blends in our work, after 30 days of immersion, is associated with the above described degradation behaviour, and after that time period it is expected that the first stage of degradation should play the main role $[3,29,30,32,33]$.

The variations in the mechanical properties when the materials are immersed, namely the observed decrease in microhardness, can be related to the different hydration degree/degradation behaviour of each material. For short periods of time, less than $100 \mathrm{~min}$, a negligible weight loss is associated with both blends, which means that the water uptake was responsible for the decrease in microhardness reported for both materials in the previous section. In the case of SCA, which presents a relatively high water uptake ability even for short immersion times, as shown in Fig. 4a, the decrease of microhardness is more accentuated. After an immersion period of 30 days the microhardness decrease could be attributed to a combination of both factors: weight loss and hydration degree. Again, SCA presents a much higher weight loss and water content than SPCL, leading to a much more pronounced decrease in its microhardness. However, even after this immersion period the hydration degree plays the main role in the variation of microhardness because it is not expected that the loss of plasticizers associated with the weight loss would contribute significantly to a decrease in microhardness.

So, the above mentioned results suggest that the water uptake is the major factor that will determine the timedependent microhardness properties in the studied samples. In another study the time variation of the loss modulus in a starch-based blend, as measured by DMA with samples immersed in a simulated physiological solution, was also correlated with swelling [15]. Such kinds of studies demonstrate the importance of the hydration effect on the mechanical behaviour of biomaterials.

\subsection{DMA and creep results}

The results of Fig. 3 clearly show the time-dependency on the microhardness behaviour in the dry SCA samples. It should be also interesting in this context to evaluate the time-dependent mechanical behaviour of the bulk materials. DMA was used in this work to characterise the viscoelastic properties of SPCL and SCA. Both materials were subjected to static (creep) and cyclic experiments.

The flexural storage modulus $\left(E^{\prime}\right)$ and loss factor $(\tan \delta)$ vs. temperature at $1 \mathrm{~Hz}$ are presented in Fig. 6. $E^{\prime}$ characterises the ability of the polymer to store energy (elastic behaviour) and it is a measure of the stiffness of the material. Tan $\delta$ is a measure of energy dissipation (damping) independent of a sample's dimensions. 


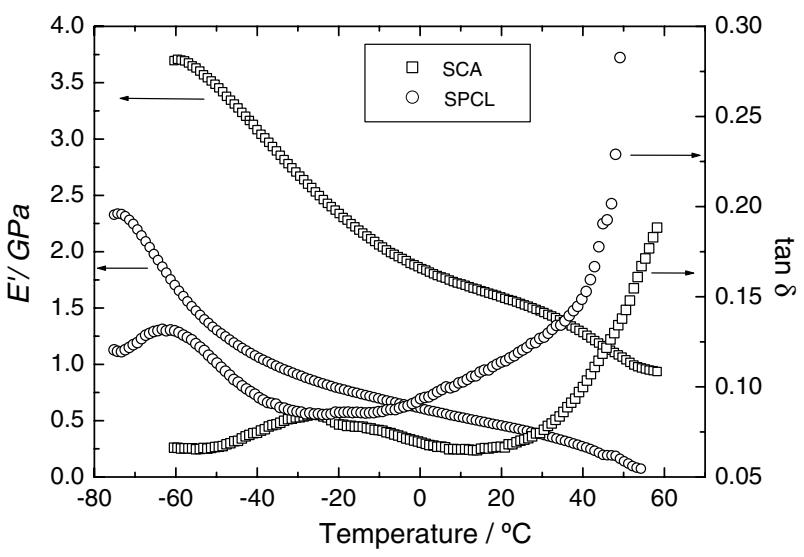

Fig. 6. Flexural storage modulus $\left(E^{\prime}\right)$ and loss factor $(\tan \delta)$ vs. temperature. The measurements were conducted at $2{ }^{\circ} \mathrm{C} \mathrm{min}^{-1}$ and at a frequency of $1 \mathrm{~Hz}$.

The dynamic mechanical behaviour of SPCL and SCA has been described elsewhere [29,34,35]. Essentially, a strong decrease of $E^{\prime}$ and a $\tan \delta$ increase is detected in SPCL at $\sim 50{ }^{\circ} \mathrm{C}$ due to the melting of the PCL fraction. Pure PCL exhibits a low glass transition temperature $T_{\mathrm{g}}$ of approximately $-60{ }^{\circ} \mathrm{C}$ [36], which can be observed in Fig. 6, which imparts a rubbery characteristic to the blend at body temperature. This means that although SPCL is not suitable for load bearing applications due to low $E^{\prime}$ values $\left(E^{\prime}=0.47 \mathrm{GPa}\right.$ at room temperature), it may be used in small defects and in areas where flexibility and good impact properties are needed. On the other side, CA is an organic ester characterized by its hardness [37], which makes SCA a more rigid material than SPCL: $E^{\prime}=1.59 \mathrm{GPa}$ at room temperature. Besides the transition regions where a decrease in $E^{\prime}$ with increasing temperature is expected, this property presents a continuous decrease with temperature in the analysed temperature range for both materials. This behaviour was also found in thermoplastic proteins plasticized with glycerol [38] and assigned to a "molecular lubricant" effect of the plasticizer.

The glass transition of starch was not detected in the temperature scans of the blends. As the starch is extruded in wet conditions before the injection moulding, the final material already underwent gelatinisation and the glass transition of starch may appear at temperatures above $60{ }^{\circ} \mathrm{C}$ [39], i.e., higher than the final temperature of our scans. The glass transition of CA was also not detected because its $T_{\mathrm{g}}$ is typically higher than the final temperature of the scan: $T_{\mathrm{g}}$ values between $147^{\circ} \mathrm{C}$ and $220^{\circ} \mathrm{C}$ have been reported [40,41], depending mainly on the acetyl content [42].

The values of the loss factor at body temperature were $\tan \delta=0.067$ for SCA and $\tan \delta=0.107$ for SPCL. These values are in agreement with the ones previously reported for these blends [34,35] and indicate that such systems, especially SPCL, are able to dissipate a significant fraction of imposed mechanical energy.

The characterization of the creep phenomenon is important from the point of view of long-term performance of

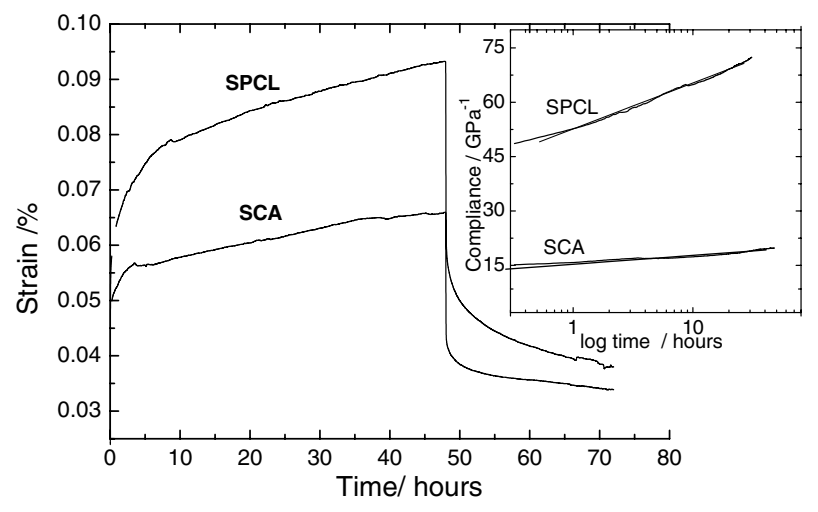

Fig. 7. Strain as a function of time measured for both blends at $20^{\circ} \mathrm{C}$. The creep stress was $3.33 \mathrm{MPa}$ for SCA and 1.21 MPa for SPCL. Creep time $=48 \mathrm{~h}$ and recovery time $=24 \mathrm{~h}$.

products. For instance it can be used for predicting the life of a product as defined by an excessive creep deformation [43]. Fig. 7 shows the creep curves obtained for both samples at $20^{\circ} \mathrm{C}$, where the strain is represented as a function of time. A detailed creep analysis of starch/PCL blends with different compositions in the extension mode can be found in the work of Sen et al. [36].

During the creep period the compliance $(D)$ of SPCL is significantly higher than that corresponding to SCA; by calculating the ratio between the deformation values and the corresponding applied stress it was found that $D_{\mathrm{SPCL}}=3.7 D_{\mathrm{SCA}}$ (see inset graphics of Fig. 7). High values of compliance for starch/PCL blends were reported before by Sen et al. [36]. The higher compliance exhibited by SPCL when compared to SCA is due to the different synthetic component of the blends. PCL has a significantly lower $T_{\mathrm{g}}$ than that of CA, as previously mentioned when the DMA results were discussed. At room or body temperatures PCL chains are above $T_{\mathrm{g}}$, hence, they are free to relax when a constant stress is applied, whereas the CA chains are still below its $T_{\mathrm{g}}$ and behave as stiff chains.

Also, the slope of the compliance vs. log time curve (Fig. 7-inset graphics) is about 4.9 times higher for SPCL. Such higher time-dependence found in SPCL in creep data is consistent with the higher $\tan \delta$ values at room temperature also found in the same material, indicating a higher viscoelastic behaviour, with respect to the more elastic features of SCA. It is interesting to note that, in contrast, the time-dependency on the microhardness results is more pronounced for SCA (Fig. 3), indicating that other factors, rather than linear viscoelasticity, are involved in the variation of microhardness with loading time.

\section{Conclusions}

Microhardness was used for the first time to evaluate the mechanical properties of starch based blends after being immersed in a physiological simulated fluid at body temperature. The main change in the mechanical properties at the surface of starch-based biomaterials under in vitro conditions occurs at time scales of a few minutes, being 
highly mediated by swelling. SCA exhibited a microhardness decrease more pronounced than PCL for the same immersion periods due to its higher hydrophilicity and higher water uptake ability.

The dependence of microhardness with loading time and load was analysed for dry SCA and SPCL. The measured microhardness was found to be load dependent and, for a given load, decreases with increasing loading time. The creep curves of SCA were successfully described by a power law.

Regarding the viscoelastic behaviour of the blends, the elastic modulus values at room temperature revealed the higher flexibility of SPCL when compared to SCA. The $\tan \delta$ values obtained indicated that both systems are able to dissipate a significant fraction of mechanical energy, especially SPCL. The more viscoelastic behaviour of SPCL was also observed from creep experiments, where it was found that the strain rate is higher for SPCL than for SCA. The compliance is about 3.7 higher in SPCL at room temperature reflecting also the higher stiffness of SCA.

The results found in this work showed that microhardness is an adequate and useful technique to monitor the mechanical properties at the surface of biomaterials upon immersion in physiological-like fluids in order to predict the mechanical performance of an implant region in contact with the tissue.

\section{Acknowledgements}

Financial support for this work was provided by FCT, through the POCTI and FEDER programmes and POCTI/FIS/61621/2004 and by the European Union funded STREP Project HIPPOCRATES (NMP3-CT-2003505758). This work was carried out under the scope of the European NoE EXPERTISSUES (NMP3-CT-2004500283).

\section{References}

[1] Galliard T, Bowler P. Morphology and composition of starch. In: Galliard T, editor. Starch: properties and potential. London: John Wiley \& Sons; 1987. p. 55-77.

[2] Reis RL, Cunha AM. Characterisation of two biodegradable polymers of potential application within the biomaterials field. J Mater Sci: Mater Med 1995;6:786-92.

[3] Reis RL, Mendes SC, Cunha AM, Bevis MJ. Processing and in vitro degradation of starch/EVOH thermoplastic blends. Polym Int 1997;16:263-77.

[4] Gomes ME, Ribeiro AS, Malafaya PB, Reis RL, Cunha AM. A new approach based on injection moulding to produce biodegradable starch based polymeric scaffolds. Biomaterials 2001;22:883-9.

[5] Espigares I, Elvira C, Mano JF, Vasquez B, San Roman J, Reis RL. New biodegradable and bioactive bone cements based on starch blends and ceramic fillers. Biomaterials 2002;23:1883-95.

[6] Gomes ME, Sikavitsas VI, Behravesh E, Reis RL, Mikos AG. Effect of flow perfusion on the osteogenic differentiation of bone marrow stromal cells cultured on starch-based three dimensional scaffolds. J Biomed Mater Res 2003;67(A):87-95.

[7] Boesel LF, Mano JF, Reis RL. Optimization of the formulation and mechanical properties of starch based partially degradable bone cements. J Mater Sci: Mater Med 2004;15:73-83.
[8] Salgado AJ, Coutinho OP, Reis RL. Bone tissue engineering: state of the art and future trends. Macromol Biosci 2004:4:743-65.

[9] Lanza RP, Langer R, Vacanti J. Principles of tissue engineering. 2nd ed. San Diego, CA: Academic Press; 2000.

[10] Reis RL, San Román J. Biodegradable systems in tissue engineering and regenerative medicine. Boca Raton, FL: CRC Press; 2005.

[11] Takeuchi K, Saruwatari L, Nakamura HK, Yang JM, Ogawa T. Enhanced intrinsic biomechanical properties of osteoblastic mineralized tissue on roughened titanium surface. J Biomed Mater Res 2005;72A:296-305.

[12] Ohya S, Kidoaki S, Matsouda T. Poly( $N$-isopropylacrylamide) (PNIPAM)-grafted gelatin hydrogel surfaces: interrelationship between microscopic structure and mechanical property of surface regions and cell adhesiveness. Biomaterials 2005;26:3105-11.

[13] Ratner BD, Chilkoti A, Castner DG. Clin Mater 1992;11:25.

[14] Wu L, Zhang J, Jing D, Ding J. "Wet-state" mechanical properties of three-dimensional polyester porous scaffolds. J Biomed Mater Res 2006;76A:264-71

[15] Mano JF, Reis RL. Viscoleastic monitoring of starch-based biomaterials in simulated physiological conditions. Mater Sci Eng A 2004;370:321-5

[16] Ania F, Dukel M, Bayer RK, Baltá-Calleja FJ. Microhardness and water sorption in injection molded starch. J Appl Polym Sci 2002:85:1246-52.

[17] Baltá Calleja FJ, Rueda DR, Secall T, Bayer RK, Schlimmer M. Influence of processing methods on starch properties. J Macromol Sci - Phys 1999;B38:461-9.

[18] Flores A, Bayer RK, Krawietz K, Baltá Calleja FJ. Elastoplastic properties of starch-based materials as revealed by microindentation measurements. J Macromol Sci - Phys 2000;B39:749-59.

[19] Bastiolli C, Cerutti A, Guanella I, Romano GC, Tosin M. Physical state and biodegradation behaviour of starch-polycaprolactone systems. J Environ Polym Degrad 1995;3:81-95.

[20] Soest JJG, Benes K, Wit D, Vliegenthart JFG. The influence of starch molecular mass on the properties of extruded thermoplastic starch. Polymer 1996;37:3543-52.

[21] Baltá Calleja FJ, Fakirov S. Microhardness of polymers. Cambridge: Cambridge University Press; 2000.

[22] Coombes AGA, Rizzi SC, Williamson M, Barralet JE, Downes S, Wallace WA. Precipitation casting of polycaprolactone for applications in tissue engineering and drug delivery. Biomaterials 2004;25:315-25.

[23] McColm IJ. Ceramic hardness. New York, NY: Plenun Press; 1990.

[24] Sangwal K, Surowska B, Blaziak P. Relationship between indentation size effect and material properties in the microhardness measurement of some cobalt-based alloys. Mater Chem Phys 2003;80:428-37.

[25] Aurrekoetxea J, Sarrionandia MA, Urrutibeascoa I, Maspoch MLI. Effects of injection moulding induced morphology on the fracture behaviour of virgin and recycled polypropylene. Polymer 2003;44: 6959-64.

[26] Baltá Calleja FJ, Santa Cruz C, Asano T. Physical transitions and crystallization phenomena in poly(ethylene-terephthalate) studied by microhardness. J Polym Sci, Part B: Polym Phys 1993;31:557-65.

[27] Boesel LF, Reis RL. The effect of water uptake on the behaviour of hydrophilic cements in confined environments. Biomaterials 2006:27:5627-33.

[28] Bastioli C. Properties and applications of mater-Bi starch-based materials. Polym Degrad Stab 1998;59:263-72.

[29] Demirgoz D, Elvira C, Mano JF, Cunha AM, Piskin E, Reis RL. Chemical modification of starch based biodegradable polymeric blends: effects on water uptake, degradation behaviour and mechanical properties. Polym Degrad Stab 2000;70:161-70.

[30] Azevedo HS, Gama FM, Reis RL. In vitro assessment of the enzymatic degradation of several starch based biomaterials. Biomacromolecules 2003;4:1703-12.

[31] Rosa DS, Guedes CGF, Pedroso AG, Calil MR. The influence of starch gelatinization on the rheological, thermal and morphological properties of poly( $\varepsilon$-caprolactone) with corn starch blends. Mater Sci Eng C 2004;24:663-70. 
[32] Mano JF, Sousa RA, Boesel LF, Neves NM, Reis RL. Bioinert, biodegradable and injectable polymeric matrix composites for hard tissue replacement: state of the art and recent developments. Compos Sci Technol 2004;64:789-817.

[33] Vaz CM, de Graaf LA, Reis RL, Cunha AM. pH-sensitive soy protein films for the controlled release of an anti-inflammatory drug. Mater Res Innov 2004;8:149-50.

[34] Mano JF, Reis RL, Cunha AM. Dynamic mechanical analysis in polymers for medical applications. In: Reis RL, Cohn D, editors. Polymer based systems on tissue engineering, replacement and regeneration. Dordrecht: Kluwer Academic Publishers; 2002. p. 139-64.

[35] Oliveira AL, Mano JF, San Román J, Reis RL. Study of the influence of the $\beta$-radiation on the properties and mineralization of different starch-based biomaterials. J Biomed Mater Res B: Appl Biomater 2005;74B:560-9.

[36] Sen A, Bhattacharya M, Stelson KM, Voller VR. Creep in injection molded starch/synthetic polymer blends. Mater Sci Eng A 2002;338: $60-9$.
[37] Ach A. Biodegradable plastics based on cellulose-acetate. J Macromol Sci 1993;A30(9-10):733-40.

[38] Vaz CM, Mano JF, Fossen M, van Tuil RF, de Graaf LA, Reis RL, et al. Mechanical, dynamic-mechanical and thermal properties of soy protein-based thermoplastics with potential biomedical applications. J Macromol Sci - Phys 2002;B41:33-46.

[39] Butler MF, Cameron RE. A study of the molecular relaxations in solid starch using dielectric spectroscopy. Polymer 2000;41:2249-63.

[40] Kim BK, Oh YS, Lee YM, Yoon LK, Lee S. Modified polyacrylonitrile blends with cellulose acetate: blend properties. Polymer 2000;1:385-90.

[41] Hatakeyama H, Yoshida T, Hatakeyama T. The effect of side chain association on thermal and viscoelastic properties of celluloses acetate based polycaprolactones. J Therm Anal Calorim 2000;59:157-68.

[42] Kamide K, Sato M. Thermal analysis of cellulose-acetate solids with total degrees of substitution of $0.49,1.75,2.46$, and 2.92. Polym J 1985;17:919-28.

[43] Trantina GG. Creep analysis of polymeric structures. Polym Eng Sci 1986;26:776-80. 